\title{
M2-Polarized Macrophages Determine Human Cutaneous Lesions in Lacaziosis
}

\author{
Tania Cristina Barboza - Mirian Nacagami Sotto (iD) Luciane Kanashiro-Galo • \\ Arival Cardoso de Brito (D) Maria Irma Seixas Duarte • Juarez Antonio Simões Quaresma (D) \\ Carla Pagliari (D)
}

Received: 19 December 2019/Accepted: 20 April 2020/Published online: 6 May 2020

(C) Springer Nature B.V. 2020

\begin{abstract}
Lacaziosis is a cutaneous chronic mycosis caused by Lacazia loboi. Macrophages are important cells in the host immune response in fungal infections. The macrophage population exhibits strong plasticity that varies according to the stimuli in the microenvironment of lesions M1 profile promotes a Th1 pattern of cytokines and a microbicidal function and M2 is related to Th2 cytokines and immunomodulatory response. We investigated the population of M1 and M2 polarized macrophages in human cutaneous
\end{abstract}

Handling Editor: Celia Maria de Almeida Soares.

Electronic supplementary material The online version of this article (https://doi.org/10.1007/s11046-020-00450-z) contains supplementary material, which is available to authorized users.

T. C. Barboza - M. N. Sotto · L. Kanashiro-Galo •

M. I. S. Duarte · C. Pagliari ( $\square)$

Laboratório da Disciplina de Patologia de Moléstias

Transmissíveis, Departamento de Patologia, Faculdade de

Medicina, Universidade de São Paulo, Av Dr Arnaldo,

455, sala 1118, São Paulo, SP CEP 01246-903, Brazil

e-mail: cpagliari@usp.br

T. C. Barboza · C. Pagliari

Programa de Pós-graduação em Ciências da Saúde, Instituto de Assistência Médica ao Servidor Público Estadual - SP, São Paulo, SP, Brazil

A. C. de Brito · J. A. S. Quaresma

Núcleo de Medicina Tropical, Universidade Federal do

Pará, Belém, PA, Brazil lesions. A total of 27 biopsies from human lesions were submitted to an immunohistochemistry protocol using antibodies to detect M1 and M2 macrophages (Arginase-1, CD163, iNOS, RBP-J and cMAF). We could observe high number of cells expressing Arginase1, CD163 and c-MAF that correspond to elements of the M2 profile of macrophage, over iNOS and RBP-J (elements of the M1 profile). The results suggest a predominant phenotype of M2 macrophages, which have an immunomodulatory role and probably contributing to chronicity of Lacaziosis.

Keywords Lacaziosis - M1 macrophages · M2 macrophages $\cdot$ Immunopathogenesis

\section{Introduction}

Lacaziosis is a chronic, cutaneous and/or subcutaneous mycosis, caused by the fungus Lacazia loboi. It mainly affects rural workers since they are in constant contact with the vegetation and soil, characteristic habitat of the fungus. The Amazon region is an important epidemiological site, where there is a high number of patients among the rubber tappers [1-4]. Lacazia loboi has a rounded form in the host (yeast), a refringent wall and homogeneous or granular cytoplasm. It is suggested that it occurs in nature in the filamentous form [5]. The lesions may present in 
different aspects: keloidiform, infiltrative, ulcerated or verrucous [6]. They may also be localized, multifocal or disseminated [7].

The pathogenesis of lacaziosis is still not well understood, since there is no culture of the agent in laboratory and the animal experiments do not yet present consistent results [8]. The individual response of the patient to the aggressions caused by Lacazia loboi varies greatly. There are individuals in which, in a short period, the lesions evolve to a more extensive and disseminated form and others that for many years persist with the localized form of the disease [9]. After infection, the incubation period is uncertain [10]. Many patients relate the appearance of lesions, especially those located in the auricle, with the arthropod bite, ticks of the Ixodidae family, which could be a type of vector [11]. Lacazia loboi seems to remain viable in diverse materials such as vegetables, soil and water.

Lesion polymorphism is the most commonly found in the clinical examination, especially in cases of long evolution. There may be black pits on the surface of the lesions, corresponding to the trans-epithelial elimination of the fungus, as occurs in other deep mycoses, such as chromoblastomycosis [12-14].

Previous studies on lacaziosis report macrophages with cytoplasm of foamy or granular aspect, similar to Gaucher cells, possibly resulting from the accumulation of fragments of the fungus, which after being engulfed, undergoes the action of the lysosomal enzymes of the macrophages. Asteroid bodies were reported present in the granulomatous infiltrate in Langhans-type multinucleated cells [8, 15].

The macrophage population exhibits strong plasticity that varies according to the stimuli in the microenvironment of lesions and can be classified as M1 or M2 type. M1 macrophages are considered to be pro-inflammatory and M2-type macrophages have an immunomodulatory profile and appear to be related to the evolution to the chronicity of infectious diseases [16].

The characterization of macrophage polarization was recently performed. The transcription factors related to this polarization were analyzed by the immunohistochemical method of double-labeling [17].

Understanding the mechanisms of lesions and immune response of the host in lacaziosis is important, because it is a disease whose progression can lead to a state of chronicity that makes treatment difficult. Despite the innumerable advances in understanding the fungal-host interaction in such disease, data from the literature show that much effort is still needed to increase our knowledge about the role of the innate and adaptive immune response in this mycosis of great importance in Brazil and other regions.

Considering the previous data and the tissue response in lacaziosis, we aim to characterize the macrophage populations present in lesions in order to contribute to better understanding of the phagocytic process and establishment of the disease.

\section{Materials and Methods}

\section{Biopsies}

Twenty-seven skin biopsies were selected from the files of Nucleo de Medicina Tropical - Universidade Federal do Para, Brazil, from patients with clinical and histological diagnosis of lacaziosis.

The criterion for selection of the cases was the representativeness of the sample, whose size was enough to perform all the immunohistochemical procedures.

Ten fragments of normal skin obtained from heart surgery incision and five fragments of normal skin obtained from orthopedic knee surgery without inflammatory or infectious activity at the time of surgery constituted the control group.

Lesions were isolated, located in the lower limbs. Patients were all rural workers, generally healthy, except for the injury confined to the skin, without systemic manifestations. The control group, constituted by normal skin is from the archives of Clinical Hospital, Medical School, São Paulo.

The histopathological study of the lesions was made through the staining of Hematoxylin-Eosin (HE).

The use of the material that constituted the casuistic was approved by the ethics committee of Clinical Hospital, Faculty of Medicine of University of São Paulo, under the number 191/12.

\section{Immunohistochemistry}

Immunohistochemical analysis was performed as follow: deparaffinization and rehydration in xylene 
followed by a decreasing series of ethanol solutions; blockage of endogenous peroxidase in 3\% hydrogen peroxide and antigen retrieval in TRIS-EDTA buffer pH9.0 (S2368, Dako Corporation) or citrate Buffer pH6.0 according to previous tests for $25 \mathrm{~min}$ at $95^{\circ} \mathrm{C}$. The specimens were incubated for $30 \mathrm{~min}$ in a $10 \%$ solution of skim milk followed by the incubation with the primary antibodies diluted in $1 \%$ bovine albumin solution. The anti-Arginase-1 (HPA003595, Sigma), anti-CD163 (NCL-L-CD163, Novocastra), anti-iNOS (482728 Calbiochem), anti-RBP-J (14613-1-AP, Proteintech) and anti-cMAF (sc-7866, Santa Cruz) antibodies were incubated over-night at $4{ }^{\circ} \mathrm{C}$. The Reveal Biotin-Free Polyvalent-HRP system (SPB999, SPRING BIOSCIENCE Corp,CA,USA) was used to develop the reactions and diaminobenzidine was used as the chromogen. All reactions were performed with positive and negative controls. The second ones were constituted by the use of isotype controls and the omission of the primary antibody.

\section{Quantitative and Statistical Analysis}

Immunolabeled cells were quantified in nine randomized fields in the dermis using a $\times 10$ ocular lens with a square grid and a $\times 40$ objective. The sum of the number of immunostained cells was divided by the number of fields (nine) and the result was divided by 0.0625 (area of the grid), providing the number of cells $/ \mathrm{mm}^{2}$.

The comparison of the number of positive cells/ $\mathrm{mm}^{2}$ was statistically analyzed by using the MannWhitney test with the level for significance set at $95 \%$ $(p<0.05)$.

\section{Results}

Histological sections of biopsies of Lacaziosis showed epidermis with hyperplastic or ulcerated appearance. In the stratum corneum, there was a frequent presence of fungal forms. The dermal changes were characterized by a clear band (Grenz), of variable thickness separating the epidermis from the dermal infiltrate.

The dermis of the skin lesions presented diffuse inflammatory infiltrate comprising macrophages, some asteroid corpuscles, lymphocytes, multinucleated giant cells and a large number of fungi.
The immunohistochemistry method allowed characterizing polarized macrophages of $\mathrm{M} 1$ profile by the expression of iNOS and RBP-J. M2 macrophages were visualized through the expression of Arginase-1, CD163 and c-Maf (Fig. 1).

There was a statistically significant difference between the number of cells expressing cMAF (M2) over RBP-J (M1) $(p=0.0015)$ in the group of lesions. Cells expressing cMAF were also increased in the group of lesions over the control group ( $p=0.0035)$. The expression of RBP-J was similar between lesions and normal skin ( $p=0.1015$ ) (Fig. 2).

When we compared cells expressing Arginase 1, CD163 and iNOS, the number of positive cells did not differ ( $p>0.05$ ) (Fig. 2). However, cells expressing CD163 were increased in the control group when compared to the group of lesions.

\section{Discussion}

Macrophages are key cells of the innate and adaptive immune response, important in the course of infection. Its polarization may result in cells of the M1 or M2 type [18-20].

M1 macrophages play a role as microbicidal, proinflammatory and anti-tumor with the expression of pro-inflammatory cytokines, HLA-DR, iNOS and the transcription factors pStat-1 and RBP-J [17, 21, 22].

M2 macrophages are immunomodulatory and characterized by the presence of c-MAF, Arginase-1, CD14, CD163, mannose receptor (CD 206), IL-10 and TGF- $\beta 1[23,24]$. Also, such cells are associated to chronic infectious diseases.

Polarized macrophages, as previously observed, express different markers such as iNOS and arginase, which are not specific for the identification of M1 or M2 macrophages, and once they can be detected in other cells. This could explain that in lacaziosis we did not find statistical difference among those markers in the lesions. Considering that, we evaluated the population of macrophages through the presence of iNOS and RBP-J to detect the M1 pattern and Arginase1, CD163 and cMAF to detect M2 macrophages in skin specimens. Also, bearing in mind that the expression of cMAF and RBP-J can be observed in different cells, we quantified only cells with nuclear positivity and macrophage morphology. 

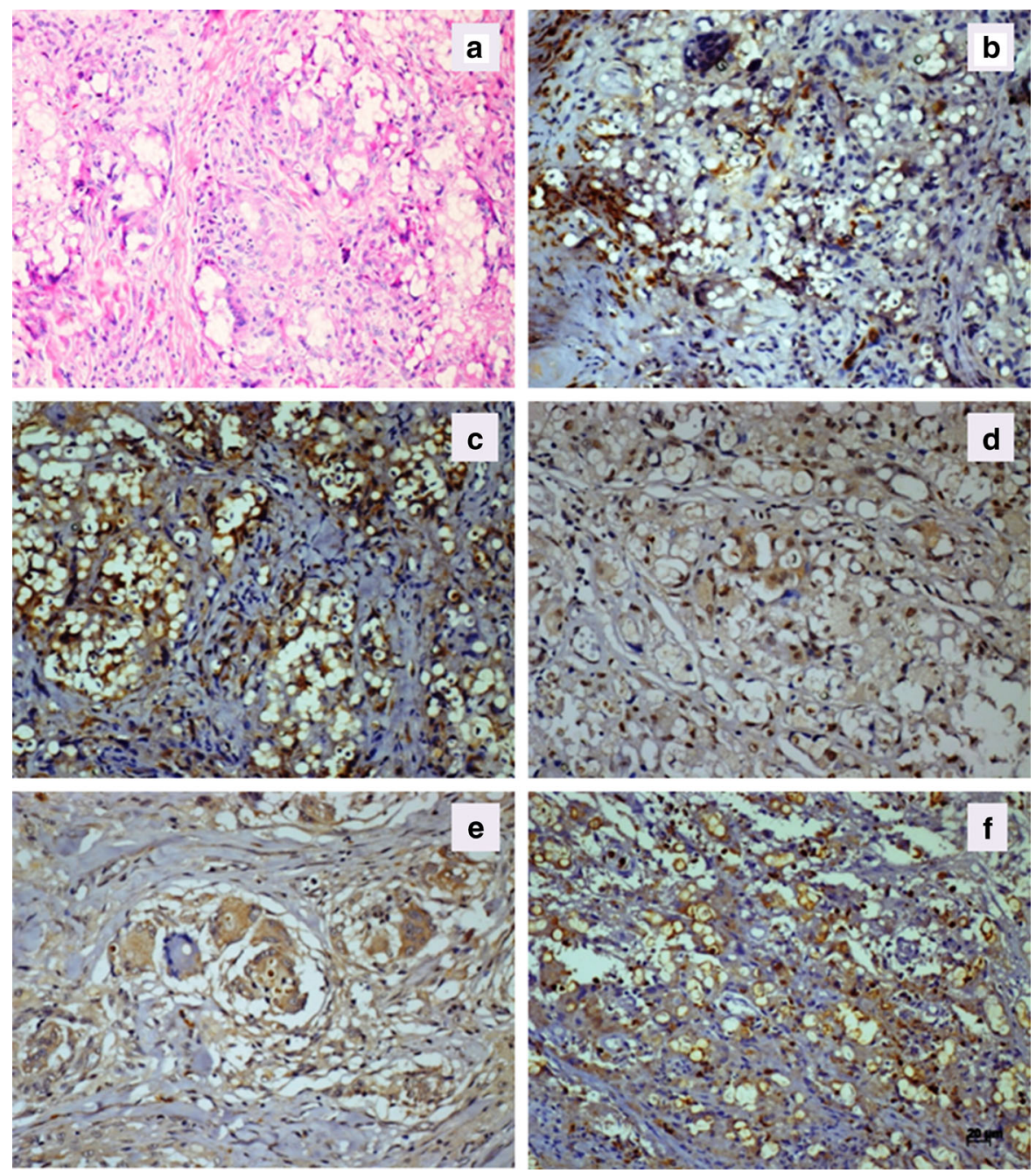

Fig. 1 Lacaziosis, skin lesions. a Inflammatory infiltrate constituted by macrophages, lymphocytes, epithelioid cells and intense number of fungal cells (Hematoxylin-Eosin); b Arginase-1 expression in the cytoplasm of macrophages; c Macrophagic cells expressing CD163; d Nuclear expression of

The transcription factor $\mathrm{cMAF}$ is related to the Th2 pattern of cytokines [17], and we detected an increased number of cells expressing this molecule when compared to RBP-J, which is related to the Th1 pattern of cytokines.

It is described that RBP-J promotes polarization of M1 macrophages in anti-tumor and anti-intracellular bacteria response [25, 26].

Based on previews reports, both CD68 and CD163 are able to identify macrophages [17]. CD163 is a specific macrophage marker, while CD68 may also identify dendritic cell subsets. That is why we added

c-MAF in macrophages; e iNOS expression in giant cells of Langhans type; $f$ RBP-J expression in the nucleus of macrophages (B-F immunohistochemistry reaction visualized in brown $)(\times 200)$

the immunostaining of the transcription factor $\mathrm{cMAF}$. This factor is related to the regulation of IL10 gene expression in macrophages and so, represents M2 macrophages. The above report used double immunostaining to support these data. On the contrary, RBP-J is related to M1 macrophages and we could observe a statistical difference when compared both markers, with predominance of cMAF in the lesions.

It seems that lacaziosis develops from a partial deficiency in the cellular immune response. The inflammatory infiltrate is composed by macrophages, 
Fig. 2 a Comparative analysis of cells expressing Arginase 1, CD163, iNOS, cMAF and RBP-J in Lacaziosis. Arginase-1:

$2.66 \pm 13.83$; CD163:

$1.73 \pm 11.23$; iNOS:

$6.22 \pm 11.17$; cMAF:

$14.22 \pm 26.53$; RBP-J:

$1.77 \pm 8.20$. b Comparative analysis of cells expressing CD163, cMAF and RBP-J

with control group

$(52.63 \pm 79.92$;

$0.00 \pm 1.80 ; 0.00 \pm 2.50$,

respectively). Values are

expressed as

median \pm standard

deviation $(* p<0.05)$
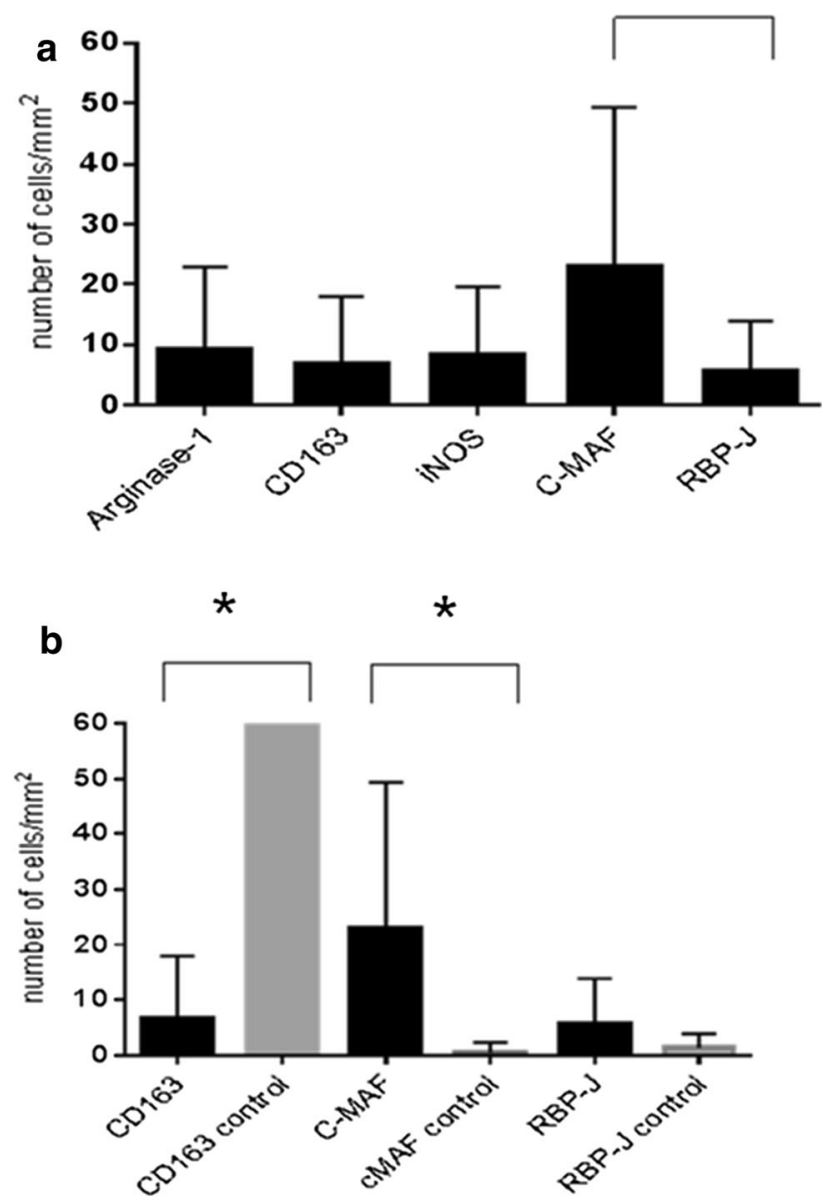

described [30], they were not detected in all specimens (only $65 \%$ ) as a result of the tissue alterations in the presence of high number of fungal cells.

The polarization of macrophages was previously observed both in viral and bacterial infections such as Listeria monocytogenes, Salmonella typhimurium, Mycobacterium tuberculosis, Mycobacterium ulcerans, and Chlamydia infections. Some bacteria interfere in M1 polarization in order to reduce inflammation and microbicidal function, for example inhibiting NF-kB activity or secreting factors that inhibit M1 activation. M. tuberculosis subverts the inflammatory response and stimulates $\mathrm{M} 2$ polarization [16, 31-35].

Some viruses take advantage on the polarization of macrophages as an escape mechanism, but contrary to bacterial infections, they commonly activate M1 macrophages. For example, hepatitis $\mathrm{C}$ virus (HCV) promotes a chronic inflammatory infection, often leading to fibrotic cirrhosis and hepatocellular found in perivascular regions. Although lacaziosis lesions also present such cells, as we previously 
carcinoma [36]; however, during infection by coronavirus (SARS-CoV), lung damage resulting from viral infection and dysregulation of the host immune response progresses to diffuse alveolar damage, resulting in acute respiratory distress syndrome and pulmonary fibrosis [37]. Cytomegalovirus polarizes monocytes to a M2 phenotype, with high expression of CD163 [38]. Finally, it is described that the receptor DC-SIGN from M2 macrophages facilitates HIV-1 entry, DNA synthesis and transmission to CD4 $+\mathrm{T}$ cells [39].

Our results, corroborated by other authors, suggest that both M1 and M2 macrophages are present in the microenvironment of lesions of lacaziosis, with a predominance of M2 population. As described in the interaction with different pathogens, the unbalance between M1 and M2 macrophages results in severe damage to the host, where the prevalence of M2 macrophages stimulates severe immunomodulation and support the maintenance of fungal forms in the lesions.

Funding This work was supported by National Council for Scientific and Technological Development (CNPq), Grant 470512/2013-0. TCB was supported by a doctor's degree fellowship from Coordination for the Improvement of Higher Education Personnel (CAPES).

\section{Compliance with Ethical Standards}

Conflict of interest The authors state no conflict of interest.

\section{References}

1. Lobo J. A case of blastomycosis produced by a new species found in Recife. Rev Med Pernamb. 1931;1:763-75.

2. Taborda PR, Taborda VA, McGinnis MR. Lacazia loboi gen. nov., comb. nov., the etiologic agent of lobomycosis. J Clin Microbiol. 1999;37:2031-3.

3. Lacaz CS, Baruzzi RG, Rosa MCB, editors. Doença de Jorge Lobo. São Paulo: USP-IPSIS; 1986.

4. Opromolla DVA, Taborda PRO, Taborda VBA, Viana D, Furtado JF. Lobomycosis: report of 40 new cases. An Bras Dermatol. 1999;74:135-41.

5. Herr RA, Tarcha EJ, Taborda PR, Taylor JW, Ajello L, Mendoza L. Phylogenetic analysis of Lacazia loboi places this previously uncharacterized pathogen within the dimorphic Onygenales. J Clin Microbiol. 2001;39:309-14.

6. Silva D. Lobomycosis. Rev Soc Bras Med Trop. 1972;6:85-98.
7. Opromolla DVA, Belone AFF, Taborda PRO, Taborda VBA. Clinic-pathological correlation in 40 cases of lobomycosis. An Bras Dermatol. 2000;75:425-34.

8. Brito AC, Quaresma JAS. Lacaziose (Doença de Jorge Lobo): revisão e atualização. An Bras Dermatol. 2007;82:461-74.

9. Opromolla DVA, Baruzzi RG. Doença de Jorge Lobo. In: Coura JR, editor. Dinâmica das Doenças Infecciosas e Parasitárias. Rio de Janeiro (RJ): Guanabara Koogan; 2005. p. 1185-92.

10. Lacaz CS, Baruzzi RG, Rosa MCB. Doença de Jorge Lobo. São Paulo: Editora da USP-IPSIS Gráfica e Editora; 1986. p. 92 p.

11. Silva D, Macedo C, Oliveira C, Unger D. Micose de Jorge Lobo simulando forma gomosa: um caso raro. An Bras Dermatol. 1996;71:211-3.

12. Opromolla DVA, Vilani-Moreno FR, Belone AFF. A doença de Jorge Lobo e a coloração pela prata metenamina. An Bras Dermatol. 1999;74:345-9.

13. Leite JM. Doença de Jorge Lobo (Estudo clínico-patológico com apresentação de cinco casos). Atas do Simpósio sobre Biota Amazônica, V.6 (patologia), pp 161-76, 1967.

14. Fuchs J, Mildbrat R, Pecher AS. Lobomycosis (keloidal blastomycosis): case reports and overview. Cutis. 1990;46:227-34.

15. Michalany J. Corpos asteróides nas lesões granulomatosas com especial referencia a blastomicose ou doença de Jorge Lobo. Rev Assoc Med Bras. 1995;2:61-8.

16. Benoit M, Desnues B, Mege JL. Macrophage Polarization in Bacterial Infections. J Immunol. 2008;181:3733-9.

17. Barros MHM, Hauck F, Dreyer JH, Kemkes B, Niedobitec G. Macrophage Polarization: an Immunohistochemical Approach for Identifying M1 and M2 Macrophages. PLoS ONE. 2013;8:e80908.

18. Gordon S, Martinez FO. Alternative activation of macrophages: mechanism and functions. Immunity. 2010;32:593-604.

19. Sica A, Mantovani A. Macrophage plasticity and polarization: in vivo veritas. J Clin Invest. 2012;122:787-95.

20. Martinez FO, Gordon S. The M1 and M2 paradigm of macrophage activation: time for reassessment. F1000 Prime Rep. 2014;6:13.

21. Puig-Kröger A, Sierra-Filardi E, Dominguez-Soto A, Samaniego R, Corcuera MT, Gómez-Aguado F, et al. Folate receptor beta is expressed by tumor-associated macrophages and constitutes a marker for M2 anti-inflammatory/ regulatory macrophages. Cancer Res. 2009;69:9395-403.

22. Movahedi K, Laoui D, Gysemans C, Baeten M, Stangé G, Van den Bossche J, et al. Different tumor microenvironments contain functionally distinct subsets of macrophages derived from Ly6C (high) monocytes. Cancer Res. 2010;70:5728-39.

23. Ambarus CA, Santegoets KCM, Van Bon L, Wenink MH, Tak PP, Radstake TRDJ, et al. Soluble immune complexes shift the TLR-induced cytokine production of distinct polarized human macrophage subsets towards IL-10. PLoS ONE. 2012;7:e35994.

24. Kong LQ, Zhu XD, Xu HX, Zhang JB, Lu L, Wang WQ, et al. The clinical significance of the CD163 + and CD68 + macrophages in patients with hepatocellular carcinoma. PLoS ONE. 2013;8:e59771. 
25. Wang H, Yang Z, Liu C, Huang S, Wang H, Chen Y, et al. RBP-J-interacting and tubulin-associated protein induces apoptosis and cell cycle arrest in human hepatocellular carcinoma by activating the p53-Fbxw7 pathway. Biochem Biophys Res Commun. 2014;454:71-7.

26. Xu H, Zhu J, Smith S, Foldi J, Zhao B, Chung AY, et al. Notch-RBP-J signaling regulates the transcription factor IRF8 to promote inflammatory macrophage polarization. Nat Immunol. 2012;13:642-50.

27. Xavier MB, Libonati RM, Unger D, Oliveira C, Corbett CE, de Brito AC, et al. Macrophage and TGF-beta immunohistochemical expression in Jorge Lobo's disease. Human Pathol. 2008;39:269-74.

28. Vilani-Moreno FR, Belone AF, Lara VS, Venturini J, Lauris JR, Soares CT. Detection of cytokines and nitric oxide synthase in skin lesions of Jorge Lobo's disease patients. Med Mycol. 2011;49:643-8.

29. Zaba LC, Fuentes-Duculan J, Steinman RM, Krueger JG, Lowes MA. Normal human dermis contains distinct populations of CD11c + BDCA-1 + dendritic cells and CD163 + FXIIIA + macrophages. J Clin Invest. 2007;117(9):2517-25.

30. Barboza TC, Quaresma JAS, de Brito AC, et al. Jorge Lobo's disease: immunohistochemical characterization of dendritic cells in cutaneous lesions. Mycopathologia. 2015;179:269-74.

31. Chacón-Salinas R, Serafín-López J, Ramos-Payán R, Méndez-Aragón P, Hernández-Pando R, Van Soolingen D, et al. Differential pattern of cytokine expression by macrophages infected in vitro with different Mycobacterium tuberculosis genotypes. Clin Exp Immunol. 2005;140:443-9.

32. Kiszewski AE, Becerril E, Aguilar LD, Kader ITA, Myers W, Portaels F, Hernàndez Pando R. The local immune response in ulcerative lesions of Buruli disease. Clin Exp Immunol. 2006;143:445-51.

33. Rottenberg ME, Gigliotti-Rothfuchs A, Wigzell H. The role of IFN-gamma in the outcome of chlamydial infection. Curr Opin Immunol. 2002;14:444-51.

34. Shaughnessy LM, Swanson JA. The role of the activated macrophage in clearing Listeria monocytogenes infection. Front. Biosci. 2007;12:2683-92.

35. Lavanchy D. Evolving epidemiology of hepatitis C virus. Clin Microbiol Infect. 2011;17:107-15.

36. Franks TJ, Chong PY, Chui P, Galvin JR, Lourens RM, Reid AH, Selbs E, Mcevoy PL, Hayden DL, Fukuoka J, et al. Lung pathology of severe acute respiratory syndrome (SARS): a study of 8 autopsy cases from Singapore. Hum Pathol. 2003;34:743-8.

37. Avdic S, Cao JZ, McSharry BP, Clancy LE, Brown R, Steain M, et al. Human cytomegalovirus interleukin-10 polarizes monocytes toward a deactivated M2c phenotype to repress host immune responses. J Virol. 2013;87:1073-82.

38. Cassetta L, Kajaste-Rudnitski A, Coradin T, Saba E, Della Chiara G, Barbagallo M, et al. M1 polarization of human monocyte-derived macrophages restricts pre and post-integration steps of HIV-1 replication. AIDS. 2013;27:1847-56.

39. Cassol E, Cassetta L, Rizzi C, Gabuzda D, Alfano M, Poli G. Dendritic cell-specific intercellular adhesion molecule-3 grabbing nonintegrin mediates HIV-1 infection of and transmission by $\mathrm{M} 2 \mathrm{a}$-polarized macrophages in vitro. AIDS. 2013;27:707-16.

Publisher's Note Springer Nature remains neutral with regard to jurisdictional claims in published maps and institutional affiliations. 